\title{
IMPLEMENTASI FUNGSI MANAJERIAL KEPALA MADRASAH DALAM MENINGKATKAN MUTU PENDIDIKAN DI MAN 2 KARAWANG
}

\author{
Tika Kurnia, Sayan Suryana \\ Fakultas Agama Islam Universitas Singaperbangsa Karawang \\ Korespondensi: Jl. HS.Ronggo Waluyo, Puseurjaya, Kec. Telukjambe Tim., Kabupaten Karawang, \\ Jawa Barat 41361 \\ e-mail: 1610631120062@student.unsika.ac.id sayan.suryana@fai.unsika.ac.id
}

\begin{abstract}
Education has a very important role for the life of the nation, state and religion. With education, quality buman resources (HR) will be created. HR has a controlling role in optimizing education, therefore management is needed. On this basis, it is necessary to have HR management in an educational institution to be able to manage an optimal performance so as to create an educational institution (school / madrasa) that is of good quality and obtain a good quality of education. From the description, the researcher chooses one of the objects in MAN 2 Karawang to be able to know: 1) Planning for madrsah Heads, 2) Organizing for Madrasah Heads, 3) Implementations of Madrasab Heads, 4) Controlling for Madrasah Heads in Developing human resource. This study uses a qualitative approach that aims to describe and analyze the managerial functions of madrasa principals which are carried out to improve the quality of education in $M A N$ 2 Karawang. Data collection techniques are carried out by means of observation, interviews and strengthened with documentation. Data analysis technique is done by reducing the data that has been collected, display data, then draw conclusions. Because this study uses a qualitative approach, it does not use the population, but uses a sample of research, namely the Head of Madrasah, KAUR Administration, Wakasek Kurilum, Wakasek Sarana, and MAN 2 Karawang Teachers as sources in gathering document. The results showed that: 1) Implementation of the Madrasab Head Managerial Function in Developing HRM as a whole was good, 2) In general there were few obstacles in developing HRM in MAN 2 Karawang, 3) The results of the managerial function of Madrasah Head who were related to the quality of education in MAN 2 Karawang looks good, as seen in: a) Obtaining accreditation A, b) Achievements obtained by students and schools, c) Producing quality graduates.
\end{abstract}

Keywords:Managerial Function, Principal of Madrasa, HR, and Quality of Education.

\section{PENDAHULUAN}

Indonesia merupakan salah satu negara berkembang yang memiliki cita-cita untuk memberdayakan semua warga negaranya agar berkembang menjadi manusia yang berkualitas sehingga mampu menjawab tantangan zaman yang selalu berubah. Salah satu upaya yang dilakukan dalam mewujudkan cita-cita tersebut adalah dengan pendidikan. Pendidikan merupakan usaha untuk mencapai sebuah tujuan tert entu yang telah dirancang atau dibuat sebelum sistem pendidikan kemudian diimplementasikan. Selain itu pendidikan 
merupakan norma dan bekal bagi kehidupan bermasyarakat, berbangsa, dan bernegara. Dalam kehidupan bernegara, kualitas sebuah bangsa akan ditentukan oleh kualitas sumber daya manusianya. Semakin tinggi kualitas sumber daya manusia suatu bangsa, semakin tinggi pula kualitas bangsa tersebut (Heryati dan Mumuh Muhsin, 2014:2).

Dalam mewujudkan suatu pendidikan yang bermutu tentu dibutuhkan suatu manajemen atau pengelolaan yang baik. Manajemen yang baik mengacu pada fungsifungsi manajemen itu sendiri, dimana fungsi-fungsi yang dimaksudkan tidak lain adalah Planning, Organizing, Actuating, dan Controlling.

\section{KAJIAN TEORITIK}

\section{Manajemen}

\section{Pengertian Manajemen SDM}

Manajemen sumber daya manusia (SDM) adalah teknik atau prosedur yang berhubungan dengan pengelolaan dan pendayagunaan personalia sekolah atau madrasah atau instansi (SDM), baik tenaga edukatif maupun tenaga administratif secara efektif dan efisien banyak tergantung pada kemampuan kepala sekolah atau madrasah baik sebagai manager dan pemimpin pada lembaga pendidikan tersebut (Baharuddin, 2010:61).

\section{Fungsi Manajemen SDM}

Mengenai hal ini kepala sekolah sebagai leader dalam meningkatkan kualitas peserta didik membutuhkan suatu cara dalam rangka menyusun program yang baik dalam setiap aktivitas di sekolah tersebut. Dengan kata lain, kepala sekolah diharuskan mampu menguasai dan melaksanakan secara baik fungsi-fungsi manajemen. Adapun fungsi-fungsi manajemen yaitu:

a. Perencanaan (planning)

Perencanaan adalah penentuan serangkaian tindakan untuk mencapai hasil yang diinginkan. Stoner berpendapat planning adalah proses menetapkan sasaran dan tindakan yang perlu untuk mencapai sasaran organisasi. Perencanaan bermakna bahwa kepala sekolah bersama timnya harus berpikir untuk menentukan sasaran-sasaran dikaitkan dengan kegiatan mereka sebelumnya. Kegiatan itu lebih didasari atas metode, pemikiran logis, dan analitis ketimbang pada praduga (intuitif).

b. Pengorganisasian (Organizing)

Pengorganisasian adalah dua orang atau lebih yang bekerja sama dalam cara yang terstruktur untuk mencapai sasaran spesifik atau sejumlah sasaran. Kepala sekolah harus memiliki kemampuan menentukan jenis program yang dibutuhkan dan mengorganisasikan semua potensi yang dimiliki untuk mencapai tujuan yang telah ditentukan. Setelah rencana program disusun dan pembagian tugas telah dilakukan, kegiatan selanjutnya adalah mengatur langkah ke arah sasaran organisasi yang telah ditetapkan.

c. Pelaksanaan (Actuating)

Pelaksanaan adalah fungsi manajemen yang berhubungan dengan usaha memberi bimbingan, saran, perintah, atau instruksi kepada bawahan dalam melaksanakan tugas masing-masing sehingga tugas tersebut dapat dilaksanakan dengan baik dan terarah pada tujuan yang telah ditetapkan semula. Pengarahan dilakukan untuk mengukur dan mengoreksi prestasi kerja bawahan guna memastikan bahwa tujuan organisasi di semua tingkat dan rencana yang didesain dapat dilaksanakan secara baik. Dalam 
fungsi ini, kepala sekolah dapat menjaga organisasinya tetap berada di atas rel yang benar. Kepala sekolah mengambil peranan yang lebih luas dalam menggerakkan organisasi sekolah untuk mencapai sasaran yang telah ditetapkan.

\section{d. Pengawasan (controling)}

Pengawasan adalah salah satu fungsi manajemen berupa mengadakan penilaian, dan jika perlu mengadakan koreksi sehingga apa yang dilakukan bawahan dapat diarahkan sesuai tujuan yang telah digariskan semula. Kepala sekolah yang baik harus mampu mendorong aneka deviasi kembali pada rel tugas yang benar. Kegiatan pengawasan dan pengendalian ini harus dilakukan secara objektif, transparan, dan akuntabel (Danim, 2009:7) .

\section{Manajemen Sumber Daya Manusia}

Menurut Marwansyah(2010:3) MSDM adalah pendayagunaan sumber daya manusia di dalam organisasi yang dilakukan melalui fungsi-fungsi perencanaan sumber daya manusia, rekrutmen, seleksi, pengembangan sumber daya manusia, perencanaan dan pengembangan karir, pemberian kompensasi dan kesejahteraan, keselamatan dan kesehatan kerja, serta hubungan industrial.

\section{Tujuan dan Fungsi MSDM}

Menurut Soekidjo Notoatmodjo (2009:118) mengatakan bahwa tujuan utama manajemen sumber daya manusia (MSDM) adalah untuk meningkatkan kontribusi sumber daya manusia (karyawan) terhadap organisasi dalam rangka mencapai produktivitas organisasi yang bersangkutan. Hal ini dapat dipahami bahwa semua kegiatan organisasi dalam mencapai misi dan tujuannya tergantung kepada manusia yang mengelola organisasi itu. Oleh sebab itu, sumber daya tersebut harus dikelola sedemikian rupa sehingga bedaya guna dan berhasil guna dalam mencapai misi dan tujuan organisasi.

Pada lingkup organisasi pendidikan, fungsi manajemen sumber daya manusia, mencakup kegiatan antara lain sebagai berikut: (1) perencanaan, (2) pengadaan, (3) seleksi, (4) orientasi, (5) penempatan dan penugasan, (6) kompensasi dan kesejahteraan, (7) pemberdayaan, (8) pengembangan kompetensi keprofesian dan jalur karier, (9) penilaian kinerja, dan (10) pemberhentian dan pemutusan hubungan kerja (Ulfatin dan Triwiyanto, 2016: 22-23).

\section{Kepala Madrasah}

\section{Pengertian Kepala Madrasah}

Menurut Wahjosumidjo (2008:83) Kepala Sekolah dapat diartikan sebagai seorang tenaga fungsional guru yang diberi tugas memimpin suatu sekolah dimana diselenggarakan proses belajar mengajar, atau tempat dimana terjadi interaksi antara guru yang memberi pelajaran dan peserta didik yang menerima pelajaran.

\section{Kompetensi Kepala Madrasah}

Standar kompetensi sebagai hasil dari kajian akademik dibawah ini cukup representatif untuk menggambarka tugas yang harus dijalankan oleh kepala sekolah. Pada sisi lain, standar kompetensi ini dirasakan baik untuk menjadi topik-topik dalam kerangka pelatihan kepala sekolah.

a. Kompetensi di Bidang Perencanaan

1. Menyusun profil sekolah;

2. Merumuskan visi, misi, tujuan dan sasaran sekolah;

3. Menentukan fungsi-fungsi (komponen-komponen) sekolah 
yanng diperlukan untuk mencapai setiap sasaran sekolah;

4. Melaksanakan analisis atas kekuatan, kelemahan, peluang, dan ancaman terhadap setiap fungsi dan faktorfaktornya;

5. Memilih dan menentukan alternatifalternatif pemecahan setiap persoalan;

6. Merencanakan kegiatan sekolah;

7. Menyusun rencana dan program pengembangan sekolah;

8. Menyusun langkah-langkah untuk merealisasikan rencana pengembangan sekolah;

9. Membuat targer pencapaian hasil untuk setiap program sesuai dengan waktu yang ditentukan (milestone).

b. Kompetensi di Bidang Pengorganisasian

1. Mengorganisasikan kegiatan sekolah;

2. Menyusun sistem administrasi sekolah;

3. Mengembangkan kebijakan operasional sekolah;

4. Menyusun sistem pengaturan sekolah yang berkaitan dengan kualifikasi, spesifikasi, prosedur kerja, pedoman kerja, petunjuk kerja, dan sebagainya;

5. Melakukan analisis kelembagaan tentang struktur organisasi yang efisien dan efektif;

6. Menata unit-unit organisasi sekolah atas dasar fungsi;

7. Merumuskan regulasi sekolah berdasarkan peraturan perundangundangan yang berlaku;

8. Menyusun mekanisme koordinasi antar unit-unit organisasi sekolah.

c. Kompetensi di Bidang Implementasi Program
1. Melaksanakan kegiatan yang telah direncanakan;

2. Memberikan pengarahan dan penugasan kepada staf atas dasar tugas dan fungsi staf yang bersangkutan;

3. Memotivasi dan mengarahkan staf supaya bekerja secara bertanggungjawab sesuai dengan tugas dan fungsinya;

4. Melaksanakan regulasi sekolah secara tepat dan mendorong penegakan hukum;

5. Menyiapkan input/sumber daya manajemen untuk mengelola sumber daya.

d. Kompetensi di Bidang Pengendalian Program

1. Merumuskan sistem pengendalian/monitoring dan evaluasi sekolah;

2. Menggunakan teknik-teknik monitoring dan evaluasi;

3. Sosialisasi dan pelaksanaan monitoring dan evaluasi;

4. Merumuskan hasil analisis data monitoring dan evaluasi.

e. Kompetensi Memimpin Sekolah

1. Memberikan keteladanan dalam sikap dan tindakan;

2. Mengarahkan guru, staf dan siswa;

3. Memiliki kekuatan dan kesan positif untuk mempengaruhi bawahan dan orang lain;

4. Mengambil keputusan secara terampil (cepat dan tepat);

5. Melakukan perubahan (inovasi) sekolah;

6. Berkomunikasi secara lancar; 
7. Melakukan kegiatan yang bersifat kreatif.

f. Kompetensi Melakukan Supervisi

1. Merumuskan arti, tujuan dan teknik supervisi;

2. Menyusun program supervisi pembelajaran;

3. Melaksanakan program supervisi;

4. Membimbing guru, staf dan siswa;

5. Mengajarkan wawasan/pengetahuan baru;

6. Melaksanakan umpan balik dari hasil supervisi (Danim, 2012:86).

\section{Manajerial Kepala Madrasah}

Dinas pendidikan telah menetapkan bahwa kepala sekolah harus mampu melaksanakan pekerjaannya sebagai edukator, manajer, administrator, dan supervisor (EMAS). Dalam perkembangan selanjutnya sesuai dengan kebutuhan masyarakat dan perkembangan zaman, kepala sekolah juga harus mampu berperan sebagai leader, innovator, dan motivator di sekolahnya. Dengan demikian, dalam paradigma baru manajemen pendidikan, kepala sekolah sedikitnya harus mampu berfungsi sebagai edukator, manajer, supervisor, leader, innovator, motivator (EMASLIM) (Mulyasa, 2011:98).

\section{Gaya/Tipe Kepemimpinan}

Dalam sebuah lembaga pendidikan tentu ada seorang pemimpin, kemudian sebagai seorang pemimpin tentu mempunyai gaya kepemimpinan. Di bawah ini macam-macam gaya kepemimpinan.

a. Tipe Otokrasi/Otoriter

Otokrasi merupakan pemerintahan atau kekuasaan yang dipegang oleh seseorang yang berkuasa secara penuh dan tidak terbatas masanya. Sedangkan yang memegang kekuasaan disebut otokrat yang biasanya dijabat oleh pemimpin yang berstatus sebagai raja atau yang menggunakan system kerajaan. Sedangkan dilingkungan sekolah bukan raja yang menjadi pemimpin akan tetapi kepala sekolah yang memiliki gaya seperti raja yang berkuasa mutlak dan sentral dalam menentukan kebijakan sekolah (Partanto \& Dahlan, 1994:952).

\section{b. Tipe/Gaya Laissez-Faire}

Kepala sekolah sebagai pemimpin bertipe laissez-faire menghendaki semua komponen pelaku pendidikan menjalankan tugasnya dengan bebas. (Sutarto, 1998:7).

c. Tipe/Gaya Karismatik

Beberapa orang pemimpin yang tergolong dalam tipe di bawah ini adalah Iskandar Zulkarnaen, F. Kennedy, Soekarno, serta Gandhi. Pemimpin tergolong tipe ini pada umumnya memiliki kewibawaan yang sangat besar terhadap pengikutnya.

d. Tipe/Gaya Demokratis

Tipe kepemimpinan ini paling tepat untuk memimpin organisasi modern. Beberapa sifat dari tipe ini adalah: 1) Selalu bertitik tolak dari rasa persamaan hak dan persamaan kewajiban sebagai manusia, 2) Berusaha menyingkronkan kepentingan dan tujuan organisasi dengan kepentingan dan tujuan pribadi bawahan, 3) Senang menerima sara, pendapat, dan kritik, 4) Mengutamakan kerja sama kelompok dalam pencapaian tujuan organisasi, 5) Memberikan kebebasan yang seluas-luasnya kepada bawahan untuk melakukan tugas, pekerjaan dalam arti bahwa ada toleransinya terhadap kesalahan yang diperbuat oleh bawahan, 6) Berusaha memberikan kesempatan untuk berkembang kepada 
bawahan, 7) Membimbing bawahan untuk lebih berhasil daripadanya.

e. Tipe/Gaya Militeristik

Sifat-sifat seorang pemimpin yang bertipe militeristik adalah: 1) Sering menggunakan system instruksi, 2) Menyandarkan diri kepada pangkat dan jabatan, 3) Senang kepada hal-hal formalistic yang berlebih-lebihan, 4) Disiplin mati, 5) Tidak senang dikritik, 6) Menggemari upacara-upacara (Rivai \& Sylviana, 2010:288-289).

\section{Mutu Pendidikan}

\section{Pengertian Mutu Pendidikan}

Mutu memiliki arti yaitu kemampuan (ability) yang dimiliki oleh suatu produk atau jasa (services) yang dapat memenuhi kebutuhan atau harapan, kepuasan (satisfaction) pelanggan (customer) (Suryadi, 2009: 27).

Pendidikan adalah hidup. Pendidikan adalah segala pengalaman belajar yang berlangsung dalam lingkaran dan sepanjang hidup. Pendidikan adalah segala situasi hidup yang mempengaruhi pertumbuhan dan perkembangan individu (Redja Mudyahardjo, 2012: 5).

\section{Konsep Manajemen Mutu Terpadu (Total Quality Management-TQM) dalam Pendidikan}

Manajemen Mutu Terpadu (Total Quality Manajement) merupakan sistem manajemen yang mengangkat sesuatu sebagai strategi (strategy) usaha yang berorientasi pada kepuasan pelanggan dengan cara melibatkan pelanggan dan seluruh anggota organisasi (syafaruddin, 2016:31).

Manajemen mutu terpadu dalam pendidikan harus menempatkan pelanggan dan produk. Jennifer A. Earnshar, berpendapat agar dalam bidang pendidikan tercapai kebutuhan pelanggan hari ini dan mendatang, maka diperlukan pengembangan kurikulum secara terusmenerus berdasarkan suara hati dari pasar yang telah diteliti (Syafaruddin, 2016:47).

\section{Manajemen Peningkatan Mutu \\ Madrasah}

Manajemen peningkatan mutu sekolah adalah suatu metode peningkatan mutu yang bertumpu pada sekolah, mengaplikasikan sekumpulan teknik, mendasarkan pada kesediaan data kuantitatif-kualitatif, dan pemberdayaan semua komponen sekolah untuk secara berkesinambungan meningkatkan kapasitas dan kemampuan organisasi sekolah guna memenuhi kebutuhan peserta didik dan masyarakat. Manajemen peningkatan mutu memiliki prinsip-prinsip sebagai berikut:

a. Peningkatan mutu harus dilaksanakan di madrasah.

b. Peningkatan mutu hanya dapat dilaksanakan dengan adanya kepemimpinan yang baik.

c. Peningkatan mutu harus didasarkan pada data dan fakta, baik bersifat kualitatif maupun kuantitatif.

d. Peningkatan mutu harus memberdayakan dan melibatkan semua unsur yang ada di madrasah.

e. Peningkatan mutu memiliki tujuan bahwa madrasah dapat memberikan kepuasan kepada siswa, orang tua dan masyarakat (Winarti, 2012:348).

\section{METODE PENELITIAN}

Menurut Rukin (2019:6)Penelitian kualitatif adalah riset yang bersifat deskriptif dan cenderung menggunakan analisis 
dengan pendekatan induktif. Penonjolan proses penelitian dan pemanfaatan landasan teori dilakukan agar fokus penelitian sesuai dengan fakta dilapangan. Selain itu landasan teori juga bermanfaat untuk memberikan gambaran umum tentang latar belakang penelitian dan sebagai bahan pembahasan hasil penelitian.Penelitian ini menggunakan pendekatan kualitatif yang bertujuan untuk mendeskripsikan dan menganalisa fungsi manajerial kepala madrasah yang dilakukan untuk dapat meningkatkan mutu pendidikan di MAN 2 Karawang. Teknik pengumpulan data dilakukan dengan cara observasi, wawancara dan dikuatkan dengan dokumentasi. Teknik analisis data dilakukan dengan cara mereduksi data yang telah dikumpulkan, display data, kemudian menarik kesimpulan.

\section{HASIL DAN PEMBAHASAN}

\section{Perencanaan Kepala Madrasah dalam Mengembangkan SDM}

kepala madrasah sudah sangat sesuai dengan teori yang pertama tentang sebuah perencanaan yang mana kepala madrasah memiliki upaya dan tujuan inti dalam sebuah proses manajerial dalam meningkatkan mutu pendidikan yang ada di sekolahnya. Namun dalam memenuhi standar mutu pendidika yang sesuai dengan teori di atas tentang standar mutu pendidikan, masih banyaknya yang perlu dikerjar atau di capai dalam memenuhi standar mutu pendidikan yang sesuai.

\section{Pengorganisasian Kepala Madrasah dalam Mengembangkan SDM}

Menurut Danim

(2009:7)

pengorganisasian adalah dua orang atau lebih yang bekerja sama dalam cara yang terstruktur untuk mencapai sasaran spesifik atau sejumlah sasaran. Kepala sekolah harus memiliki kemampuan menentukan jenis program yang dibutuhkan dan mengorganisasikan semua potensi yang dimiliki untuk mencapai tujuan yang telah ditentukan. Setelah rencana program disusun dan pembagian tugas telah dilakukan, kegiatan selanjutnya adalah mengatur langkah ke arah sasaran organisasi yang telah ditetapkan.

Dengan adanya hal di atas, beliau bisa dipastikan tidak memiliki atau mengguanakan gaya kepemimpinan demokratis di dalam proses manajerialnya. Karena dalam proses pengorganisasiannya beliau hanya memilih staf yang berpengalaman saja, akan tetapi tidak memberikan kesempatan kepada staf lain awal staf muda untuk ikut berkontribusi dalam proses manajerial yang sedang beliau lakukan.

\section{Pelaksanaan Kepala Madrasah dalam Mengembangkan SDM}

Menurut Mulyasa (2011:98) seorang manajer atau seorang kepala sekolah pada hakikatnya adalah seorang perencana organisator, pemimpin, dan seorang pengendali. Keberadaan manajer pada suatu organisasi sangat diperlukan, sebab organisasi sebagai alat mencapai tujuan organisasi di mana di dalamnya berkembang berbagai macam pengetahuan, serta organisasi yang menjadi tempat untuk membina dan mengembangkan karir-karir sumber daya manusia, memerlukan manajer yang mampu mengorganisasikan memimpin, dan mengendalikan agar organisasi dapat mencapai tujuan yang ditentukan. 
Dari pendapat ahli di atas, adanya kesesuaian dengan hasil dilapangan, yang mana seorang kepala madrasah selaku manager disebuah lembaga pendidikan sudah menjalankan tugasnya yaitu sudah mampu mengendalikan masalah atau hambatan yang terjadi disekolahnya.

\section{Pengawasan Kepala Madrasah dalam Mengembangkan SDM}

Menurut Danim (2009:7) pengawasan adalah salah satu fungsimanajemen berupa mengadakan penilaian, dan jika perlu mengadakan koreksi sehingga apa yang dilakukan bawahan dapat diarahkan sesuai tujuan yang telah digariskan semula. Kepala sekolah yang baik harus mampu mendorong aneka deviasi kembali pada rel tugas yang benar. Kegiatan pengawasan dan pengendalian ini harus dilakukan secara objektif, transparan, dan akuntabel.

Maka kesimpulannya adalah kepala madrasah belum begitu maksimal dalam proses manajerialnya terutama dalam hal pengawasannya, masih terjadinya keleluasaan yang dilakukan oleh staf bawahannya dalam hal kedisiplinannya.

\section{KEPUSTAKAAN ACUAN}

Asmani, Jamal Ma'mur. 2009. Manajemen Pengelolaan dan Kepemimpinan Pendidikan Profesional. Jogjakarta: Diva Press.

Danim, Sudarwan dan Suparno. 2009. Manajemen dan Kepemimpinan Transformasional Kekepalasekolahan: Visi dan Strategi Sukses Era Teknologi, Situasi Krisis dan Internasionalisasi Pendidikan. Jakarta: Rineka Cipta.

Danim. 2012. Profesi Kependidikan. Bandung: Alfabeta
Heryati, Yeti dan Mumuh Muhsin. 2014. Manajemen Sumber Daya Pendidikan. Bandung: CV Pustaka Setia.

Jahari, Jaja dan Amirulloh Syarbini. 2013. Manajemen Madrasah. Badung: Alfabeta.

Marwansyah. 2010. Manajemen Sumber Daya Manusia. Bandung: Alfabeta.

Mudyahardjo, Redja. 2012. Pengantar Pendidikan. Jakarta: PT RajaGrafindo Persada.

Mulyasa. 2003. Menjadi Kepala Sekolab Professional. Bandung: PT. Remaja Rosdakarya.

.2004. Menjadi Kepala Sekolah Professional. Bandung: PT. Remaja Rosdakarya.

.2011. Menjadi Kepala Sekolah Professional. Bandung: PT. Remaja Rosdakarya

Rukin. 2019. Metodologi Penelitian Kualitatif. Sulawesi: Yayasan Ahmar Cendikia Indonesia.

Suryadi. 2009. Manajemen Mutu Berbasis Sekolah Konsep Dan Implikasi. Bandung: Sarana Panca Karya Nusa.

Syafaruddin. 2016. Manajemen Mutu Terpadu dalam Pendidikan. Jakarta: Grasindo.

Terry, George R. 2006. Prinsip-Prinsip Manajemen. Jakarta: PT Bumi Aksara.

Veithzal, Rivai \& Sylviana Murni. 2010. Education Management. Jakarta: PT RajaGrafindo Persada.

Wahjosumidjo. 2008. Kepemimpinan Kepala Sekolah, Tinjauan Teoretik Dan Permasalabannya. Jakarta: Rajawali Pers.

Winarti, Sri. 2012. Manajemen Sekolah Mengelola Lembaga Pendidikan Secara Mandiri. Jogjakarta: Ar-Ruzz. 